\title{
Existential Experience of the Other: Essay on "Solaris"
}

\author{
Svetlana Rudanovskaya \\ Department of Social Philosophy \\ Faculty of Humanities and Social Sciences \\ Peoples' Friendship University of Russia \\ Moscow, Russia \\ E-mail: rudsv@live.ru
}

\begin{abstract}
Understanding of Other depends on understanding of oneself and one's own culture and is often obscured and blocked by ready-made definitions, assessments and standards of description. "Solaris" by S. Lem represents an extraordinary Other that cannot be caught or conquered with final words and conclusions. Modes of perception of Solaris analyzed in this article reflects intentions, emotional attitudes of homo sapiens, and, among them, a deep-seated desire to get rid of incalculable Other as a threat to human existence. Existential experience of the Other implies better awareness of one's personal history and almost impossible "horizontal" perception of the world where one can be with Other without attempting to make him/her manageable, predictable, hopelessly "one's own".
\end{abstract}

Keywords-Other; "Solaris"; S. Lem; anthropocentrism; observer's perspective; existential experience

\section{INTRODUCTION}

An encounter with the Other is a bifurcation point in many biographies, the trigger of the story in many travelling

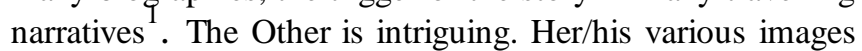
(an enemy, an alien, a crazy, Alter Ego, a representative of other outlook or life style) challenge a quotidian life and mobilize a human power to make decisions in non-standard situations. The Other, who is exception to the rules, reminds of dynamics and diversity of existence, but simultaneously undergoes the influence of social rules and their limits. The real Other, as well as fictional one, always runs the risk of being integrated in habitual frames of perception, standard plots of mass culture. The Other is always on the point of disappearing as the recognized Other.

In many popular science fiction stories an anthropomorphic figure of the supposed Other is used to stress and justify the excellence of human values and advantages of human civilization. The Other should be conquered or saved and incorporated in the accepted system of meanings to have its definite place there. In "Solaris" S. Lem describes the critical encounter between human beings and "the fundamentally other ocean" [2. P.110], who escapes any definitions of human culture and remains enigmatic for

\footnotetext{
1 "The Other is the motive for every adventure tale" [1. P.1].
}

several generations of mankind. The presence of the sentient being that can't be decoded with any known language is a challenge to linguistic, cognitive and communicative human habits ${ }^{2}$. In this case the other troubles humans with its visible availability (as a planet) and incomprehensible uncertainty (as unpredictable ocean), and provokes changes in personal self-consciousness together with the changes in ways of interpreting the complex reality in general.

\section{A DANGER OF THE OTHER}

As an object of scientific studies Solaris is defined with conceptual tools of scientific theory and perceived with standard cultural images. A scientific society tends towards an intellectual communication with the Other, avoiding any existential losses. However it turns out that Solaris is not a linguistic, but ontological Other. It doesn't matter much that he speaks an unknown language, the point is that the space of his/her vital activity is arranged on unknown experience of reality. The objects, that are totally real for astronauts, don't exist for the ocean (including the astronauts as autonomous beings). And that is not a problem of translation, intellectual communication, but the problem of differences in visions and dispositions, dissimilar life worlds ${ }^{3}$. Since a certain moment the ocean has stopped being a mere object of study which engenders theoretical curiosity of observers. Instead he/she produces processes that destroy foundations of human reality and endanger the common sense of human beholders. The situation is complicated by the fact that negativity of the Other doesn't arise from his/her malicious actions towards homo sapiens, but from a clash between incompatible views. Each of these views adheres to "one's own" mode of perception and construction of reality and rejects or ignores another.

There's no Other as a bearer of a certain message or representative of a particular way of life on the station. There are events, incidents that suggest undetectable

${ }^{2}$ As I. Csicsery-Ronay (Jr.) writes, "one of SF's jobs is to problematize the order of things" [1. P. 4] and explore "our "customary ontological habits" [1. P. 22].

${ }^{3}$ Carl D. Malmgren interprets "the encounter with speculative Otherness" as "really radical change", the passage "from one reality to another" [3. PP. 30-31]. 
deontologization of the human environment with physical reality transforming into dream-like world. In this world reality retreats and gives way to the unreal: the creatures that can't exist come into being, the past interposes into the present, matter stops offering proper resistance, all physical barriers become provisional. As in a dream an individual finds himself in milieu where the possible is accompanied by the impossible, the fantastic - by the real. The space created and run by humans ceases to be definite, steady, taken for granted, but is similar to a maze where everybody blunders around. As in a dream, an individual can't help but observing and enduring the scenes that evolve without his participation or influence 4 . Simultaneously in this dream-like world there is no opportunity to shift to other decorations, change the scene or just wake up. It's a dream without exit.

The presence of the Other doesn't give rise to any evident disasters (that humans should be ready to face), but inverts the habitual order, produces a number of psychological shifts which leave an individual without his personal space and the possibility to keep an inner balance. A personal space is an indispensable condition of reasonable relations with the Other, a guarantee of one's security and personal freedom. On the station a personal space turns out to be "occupied" by uninvited "visitors", objectified images from astronauts' subjective experience. The visitors are extracted from humans' memory and provided with halfautonomous existence, which is possible only within the station and only in close proximity to its origins (the astronauts). "Mild" intrusion of the visitors, though has nothing to do with direct aggression, nevertheless hurts, for the visitors embody "sore points", depths of unconsciousness which are difficult to talk about. The significant figures from the past don't leave astronauts alone, embrace the senses, fix the attention on unsolved interpersonal relationship, stress fragility of homo sapiens, thus undermining the stance of independent observer from the inside [5. P.13]. The personal space appears to be occupied with automatic inflow of subjective stuff that at the same time ceases to belong to essentially intimate experience.

The Other acts as a psychoanalyst who extracts the repressed desires out of the unconsciousness, though contrary to a psychoanalyst the Other can do without human confessions and step-by-step interpretations of their images. The Other doesn't speak, but catches the depths of memory, avoiding the defense mechanism of the mind. Between the individual consciousness and unconsciousness there appear no mediums, buffer zones, symbols, indefiniteness. The facts of individual life are being alienated from persons, bereft of their own faults, tests, losses, in other words - their own histories. All in all the process reminds a psychological aggression. The effect of conquering and expropriation increases due to the fact that figures from personal biographies, significant for the person, are pushed into nonhuman space, indifferent towards the frontiers between the inner and outer life, the subjective and objective reality,

\footnotetext{
${ }^{4}$ It's indicative that one of astronauts, Snow, gives the following advice to a newcomer, Kelvin: "If you should see anyone else - someone who isn't me or Sartorius, you understand, then . .." - ""Then what?"... " In that case, do nothing" [4]
}

living creatures and non-living anymore. What's more, cut off from the organic wholeness of human memory, those figures signify the total transformation of individual who is forced to become an object of alien observation and during this observation has been reduced to one fragment of his painful past. An indefinite Other, that manifests a photographic precision in psychosomatic reproduction of figures from human unconsciousness, totally deprives humans of their indefiniteness, variability, inner time, a possibility to plunge into themselves.

\section{THE OTHER AND SELF-DISCOVERY}

The Other is dangerous as he threatens to incorporate humans into one's own system of perception without human frontiers and distances, without any notion of others. As far as Solaris' creativity is concerned, it is monologic, relies on analytical "extraction", destruction of the barriers, the detailed attestation of the unknown objects. In this sense Solaris is a distorted mirror of human inclination to objectify and analyze things abstractly.

The alien milieu that astronauts go through is, first of all, the result of objectified human experience, stripped from the historic temporality. The astronauts involuntary participate in producing the alien routine due to the fact that they are by any means longing to remain the beings they are. The closed reality of reappearances reflects the steady layers of human psychology, clusters of memory unchangeable during the lifetime. Nevertheless besides the negative experience of the Other, the astronauts are engaged in the process of selfobservation, revising deep-seated personal convictions. The world of "eternal return", however inhuman it may be, sets limits to human expansion (psychological, cosmological), forces human beings to doubt their cognitive and communicative strategies. The only foothold left for people on the station is the position of an observer, accepted not as a privilege, but as the last fort post of human selfconsciousness, the reality that allows astronauts to maintain the clarity of thought despite a schizoid element.

Against the background of "eternal return" humans' reality appears discrete, punctual, concentrated in single ironical remarks, heart-to-heart talks which are supposed to restore the lost meanings and temporal links. While blocking a day-to-day speech, the Other enforces the astronauts to be sincere with themselves and each other, participate in dialogues full of paradoxes and bitter truths, that unmask an abstract image of homo sapiens and at the same time introduce the experience of homo suffering, unknowing, absurd (being in anguished search of one's authentic image). This homo is both ridiculous, as he always come back to the same errors, "idols of consciousness", and tragically lonely as he goes on brooding and speaking, making descriptions of things, going to library in the vacuum of words and relations meant nothing for the Other. The astronauts' confessions are the confessions of those who have nothing to hide, have nobody to deceive; the only thing they can do is to be honest, get rid of melodramatic effects.

The style of narrative here and there is close to the style of "The Stranger" by A. Camus. It's precise in describing the 
facts which are senseless and it's laconic in expressing the thoughts of humans in boundary situation, between life and death. Kelvin's confessions reminds of the "stranger's": "All at once I was filled with a dull indifference. I saw myself, I saw both of us, from a long way off, as if through the wrong end of a telescope, and everything looked meaningless, trivial, and slightly ridiculous" [4]. However "the stranger" holds the principle of intellectual honesty which results in radical personal refraining from emotional participation in symbolic interactions. The vision of the stranger stresses the artificial shallow character of various social habits and words and in this sense makes them meaningless. The astronauts in "Solaris" hold the principle of intellectual honesty too, but this principle in the end encourages them to recognize the existence of a non-human reality with its own meanings which are always misunderstood under dogmatic human perception. Unlike "the stranger" who distances himself from the world of common sense, his "native" world, the astronauts are "guests" who go through the crisis of their historical identification since their cultural baggage turns out to be insufficient to understand the Other. And if "the stranger" in Camus' novel states the loneliness of the reason in the presence of non-human (inhuman) reality, 'the guests' in Solaris assert themselves in search of communication, submitting to complex reality with multiple forms of sensible life $^{5}$.

\section{THE OTHER AS LIVING BEING}

"Solaris" starts and finishes with human lack of knowledge. At the beginning of the story the lack of knowledge pains as its source is the Other, that can't be caught with human reason. At the end of the story the lack of knowledge is a fact that astronauts recognize embracing the complex reality that exceeds human imagination and puts limits to human rational conclusions. A few seconds of direct observation of the ocean after fruitless theoretic activities help Kelvin focus on the living Other as it is, with all its evident existence which can't be omitted, diverged from or labeled willfully. That non-verbal and non-instrumental attitude towards the Other engenders a feeling of something wonderful that exists nearby and that was out of sight before: "I had never felt its gigantic presence so strongly, or its powerful changeless silence, or the secret forces that gave the waves their regular rise and fall" [4].

This attitude, free from ready-made knowledge, preunderstanding, liberates the Other from verbal limits of cultural language. The Other "keeps silence" in response to the suspense in the stream of human consciousness with its intentions to oppress and sublime the experience of the unknown. A protagonist describes this experience as sinking into "a universe of inertia" [4]. Nevertheless, it is a new form of the observer's activity that includes co-feeling with another living creature. Contrary to the previous forms, it is based on no abstract ideas, but on the personal assurance that this creature is alive and in its living activity somehow

\footnotetext{
5 "Occupying the position of the Other also serves to circumscribe the Self" [3. P. 25].
}

responds to the strongest and deepest impressions of the person.

The Other neither speaks nor directly addresses the beholder. It is discovered as a manifestation of life in its natural originality and inventiveness without any "will to power", purposeful cruelty, rejection of Other living beings. This form of life is fraught with irresistible eagerness to variability, novelty, constant eagerness to transcend the given experience or mechanical predetermination: "In all their movements, taken together or singly, each of these branches reaching out of the ocean seemed to display a kind of cautious but not feral alertness, a curiosity avid for quick apprehension of a new, unexpected form, and regretful at having to retreat, unable to exceed the limits set by a mysterious law" [4].

Nevertheless disinterested experience of the Other released from the anthropocentric care about oneself isn't free from an anthropocentric search of the meanings corresponding to the general principles of reasonable reality where any form of life has its meaning. In the presence of the Other there appears an irresistible human bias to find meaning in any situation; and even when the meaning is lost, a thought makes a jump from a "silent reality" to "a mysterious one", from a strange other to the Other which is creative and full of the new positive possibilities.

A feeling of piety towards the enormous wonderful Other is accompanied by the feeling of compassion towards another living being who appears limitless in its abilities but turns out to be vulnerable and ignorant in its communicative capacities. A representative of Homo Sapiens can't get the point of view of "fluid colossus" (and unlikely to do it in the future), however in his climax intuition he understands the framework of everybody's existence: that is existence without perfect knowledge and right understanding, characterized by the periods of trials and errors, absurd causalities. According to this insight everybody's experience is "naïve", similar to childish attempts to travel through reality.

Approaching the Other, alive and imperfect, produces a change in human self-consciousness, fosters a drastic transformation, replacing the tendency to arrange things with the intention to understand the importance of what it is, the politics of self-defense - with the reassessment of relations between a person and his environment. The Other liberates humans from the invisible power of "one's own culture", lets them be different, act against the accepted models of the technological civilization, take risk of being ignorant, disarmed, paradoxical (that is the risk of being ready to experience both solitude and hope for something wonderful). The Other allows humans to obtain the extent of sincerity and open-heartedness (first of all with themselves) which can't be possible in pragmatic communications, delineated by the commercial purposes (calculations of benefits and losses) as well as never-ending apprehension of possible defeat. "The fundamental Other" is a danger and the outlet for homo sapiens, a chance to get rid of false ideas, artificial identifications, traps of the ratio (in the moments of outmost frankness, deep understanding, recognition of the Other). 


\section{CONCLUSION}

To some extent Solaris is a universal Other, who challenges traditions of rational thought and makes humans reflective about the grounds of their culture and actions. At the same time he/she is a unique other, who acts behind the sphere of social communication, playing no parts, competing for nothing. While probing various possibilities of creating and exploring the world, Solaris doesn't hide or suppress anything and doesn't ponder over the possible conflicts arising from his/her activity. The Other is straightforward and naked, comprehends no constraints from without, is unceremonious towards the limits accepted by the common sense; in sum he/she reminds of something primitive and far from the artificial technological environment: "In the distance, there was a faint noise of bare feet padding over the floor. The muffled echo of these shuffling steps reverberated eerily among the nickel-plated and laminated equipment and the tall shafts, furrowed with glass tubes, which encased the complicated electronic installations" [4].

Being deadly dangerous, the Other is also attractive. His/her freedom of expression refers to the abundance of life that is open to any combinations, knows nothing about vice and virtue, the possible and impossible. Turning back to the Other after confrontations and disappearance of grounds means turning back to basics as well as to mythological times when no models of behavior and thought were established once and for all, when quotidian life with its accepted definitions and limits didn't exist.

\section{REFERENCES}

[1] Csicsery-Ronay I. (Jr.) Some Things We Know about Aliens // The Yearbook of English Studies, V. 37, N 2, Science Fiction, 2007. - PP. 1-23. http://www.jstor.org/stable/20479299 (12.01.2015).

[2] Freedman C. Critical Theory and Science Fiction. - Middletown, Connecticut: Wesleyan University Press, 2000 (Kindle Edition).

[3] Malmgren Carl D. Self and Other in SF: Alien Encounters // Science Fiction Studies, V. 20, N 1 (March, 1993). - PP. 15-33 http://www.jstor.org/stable/4240211 (12.01.2015).

[4] Lem S. Solaris. Translated from the French by Joanna Kilmartin and Steve Cox. Faber and Faber, 2003. 224 p.

[5] Csicsery-Ronay I. (Jr.) The Book is the Alien: On Certain and Uncertain Readings of Lem's Solaris // Science Fiction Studies, V.12, N 1 (March, 1985). - PP. 6-21. http://www.jstor.org/stable/4239658 (12.01.2015). 